\title{
ROTTEN IN THE AIR: REVISITING COTARD'S SYNDROME
}

\author{
F. Santos ${ }^{1}$, C. Teles ${ }^{1}$, J. Marques ${ }^{1}$, A. Gomes ${ }^{1}$, S. Nascimento', T. Queirós ${ }^{2}$ \\ ${ }^{1}$ Centro Hospitalar Universoitário do Algarve; ${ }^{2}$ Centro Hospitalar Universitário Lisboa Norte
}

\section{Introduction}

First described by Jules Cotard in 1880 as a new type of agitated melancholia - "la mélancolie anxieuse grave", Cotard's Syndrome (CS) is a rare psychiatric condition in which the essential feature is the presence of nihilistic delusions concerning body or life. ${ }^{1}$

Berrios and Luque in 1995, conducted a retrospective analysis of 100 cases of CS and subdivided them in to 3 groups: first one describes a psychotic depression with prominent melancholia but few nihilistic delusions; the second group, Cotard type 1, identifies a more prominent delusional component over depression; and a third group, Cotard type 2, identifying the presence of a mix of anxiety, depression, and auditory hallucinations. The most common symptoms reported were depression $(89 \%)$, nihilistic delusions concerned with the body $(86 \%)$ and existence $(69 \%)$, anxiety $(65 \%)$, guilt $(63 \%)$, hypochondriacal delusions (58\%), and delusions of immortality $(55 \%){ }^{2}$

The development of CS seems to increase with age and no clinical differences were found between genders, although female gender appears to be more vulnerable. ${ }^{2}$

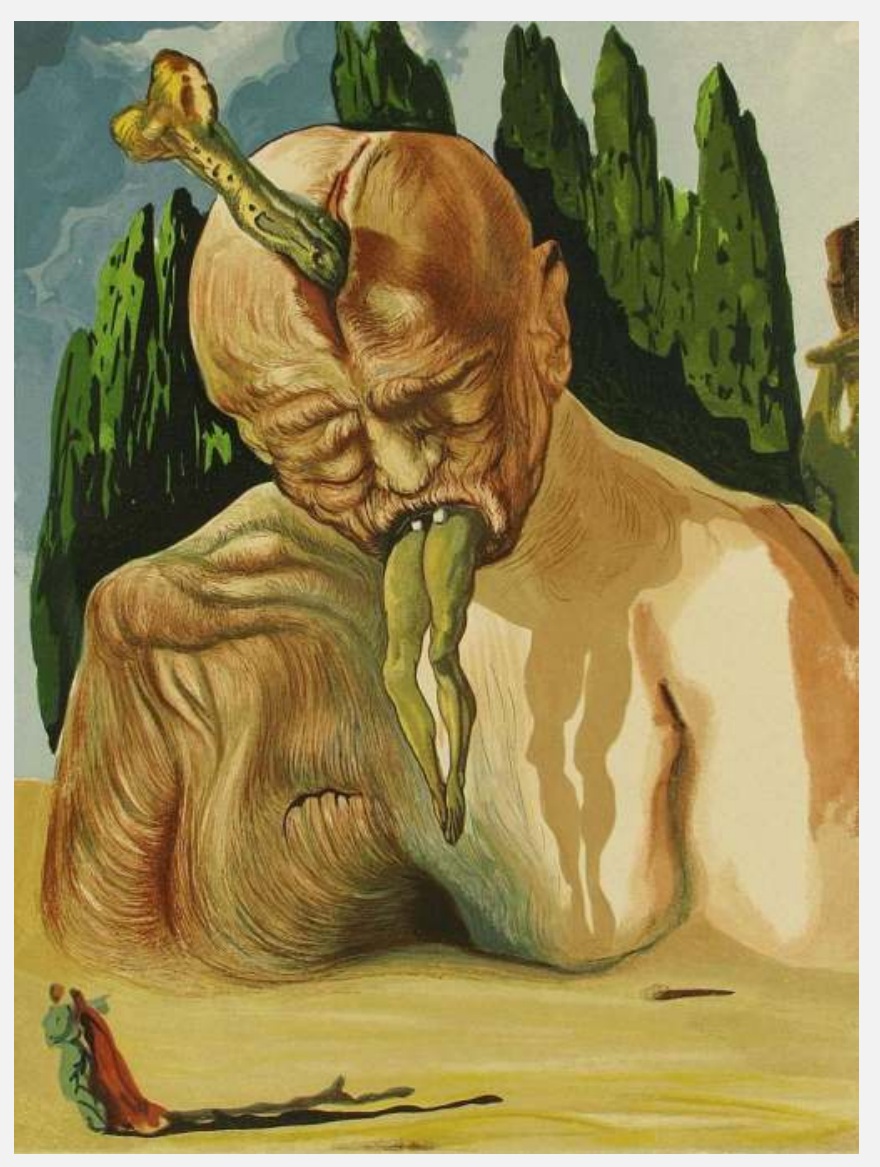

\section{Case Report}

54-year-old male, divorced, presented in the psychiatry emergency department after attempting suicide with medication.

Patient with no psychiatric history, until a visit to general hospital emergency department the month before, when he started to feel apprehensive that something was wrong with his health. He commenced to think "I might have a very bad illness (...) the doctor didnt't tell me what it is" . A few days later, he began to sense a rotten smell around him, so he decided to quit his job because "everyone could sense that smell". He isolated himself at home thinking about ending his life "I am going to die soon anyway (...) I am dead, rotten inside".

At observation he was anxious, unwilling to believe that nothing was wrong with him, presenting hypochondrial and nihilistic delusions associated with olfactory hallucinations and suicidal ideation, without other relevant psychopathology. Even though, reluctant to medical help, he accepted hospitalization in psychiatry ward.

During hospitalization, organic aetiology investigation was addressed, with no relevant findings. The patient started treatment with second generation anti-psychotic, (risperidone up to $6 \mathrm{mg} /$ day), and was discharge after 15 days, with no psychotic symptoms, including olfactory hallucinations, and no suicidal ideation.

\section{Discussion}

Although rare and described more than 100 years ago, CS still is a present phenomenon in the psychiatric wards all over the world with clinical characteristics similar to those initially observed by Jules Cotard.

Based on the delusional disorder predominance without affective symptoms and good response to anti-psychotic treatment, using the classification system by Berrios and Luque, we can consider this case as an example of Cotard's Syndrome type 1.

Nowadays, CS is not classified as an isolated disorder in the 5th edition of Diagnostic and Statistic Manual of Mental Disorders (DSM- 5) neither in the International Classification of Diseases (ICD-10), but remains an elusive condition, rarely reported and poorly researched. 